
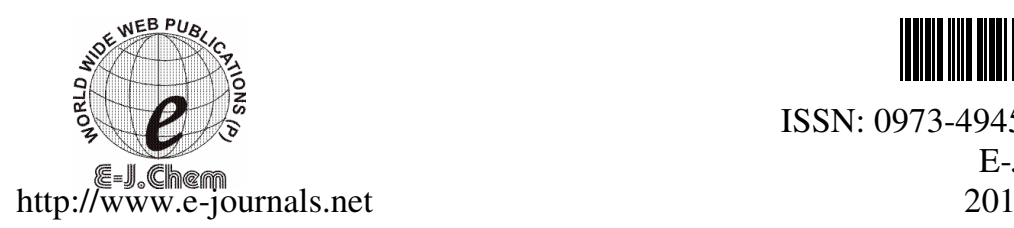

ISSN: 0973-4945; CODEN ECJHAO

E-Journal of Chemistry

2010, 7(S1), S185-S190

\title{
Mineralogical Characterization Studies of Ancient Potteries of Tamilnadu, India by FT-IR Spectroscopic Technique
}

\author{
R. RAVISANKAR ${ }^{*}$, S.KIRUBA ${ }^{\#}$, P.ESWARAN", \\ G. SENTHILKUMAR ${ }^{\S}$ and A.CHANDRASEKARAN \\ *Post Graduate and Research Department of Physics,
}

Government Arts College, Tiruvanamalai-606603, Tamilnadu, India

\#Department of Physics, St.Joseph's College of Engineering, Chennai-119, Tamilnadu, India

${ }^{\mathbb{I}}$ Department of Physics, Vel Tech Dr RR \& SR Technical University, Chennai-62, India

${ }^{\S}$ Department of Physics, University of College of Engineering

(A Constituent College of Anna University) Chennai, Arani- 632317, Tamilnadu, India

Department of Physics, Sacred Heart College, Thirupattur-635601, Tamilnadu, India

rrs_phy@rediffmail.com

Received 15 March 2010; Accepted 23 May 2010

\begin{abstract}
We report the spectroscopic investigation of ancient potteries excavated in Tamilnadu. Qualitative analyses were carried out to determine the major and minor constituent minerals present in the samples from the band position or location of the peaks. From the prominent IR absorption peaks, the minerals were identified with the available literature are the quartz, orthoclase, albite, magnetite, hematite, kaolinite, montmorillonite, illite, gypsum and calcite. The interpretation of results is made from the IR characteristics absorption bands. Spectroscopic results indicates that these potteries were refried to a less than $900{ }^{\circ} \mathrm{C}$.
\end{abstract}

Keywords: Ancient pottery, Archaeometry, FT-IR, Firing temperature, Mineralogical Characterization.

\section{Introduction}

Archaeometry is a multidisciplinary research branch which focuses on studying and solving the problem in the field of cultural heritage. This discipline is geared towards the extraction of information about the genesis and history of findings through the analysis of the material and dating techniques. Archaeometry includes studies about dating, authentication, conservation and restoring, provenance and the achievement of technological information about hand made articles manufactures as well. One of the most important areas of 
archeology is the identification of the source and the origin of ancient artifacts. Knowing the origin is very important for tracking correctly ancient civilization and history. Ancient potteries are the most common artifacts found during excavation of archeological sites, so archaeologists are interested in the studies of pottery fragments. Most archaeologists have classified ancient artifacts (pottery) by their shapes and uses. The main ingredients of pottery are clays to which tempering materials are some time added during manufacture. The clay, shell, sand etc. from which pottery were fashioned can have a chemical composition which unique and thus reviles the local source from which they were taken. Potteries are made of clay minerals and the common major clay mineral used in making potteries is kaolinte. The study of thermal transformation of the clay mineral can thus help in determining the firing temperature of the potteries.

The dehydroxylation of kaolinte minerals was first studied by Ross and Kerr ${ }^{1}$. According to their differential thermal analysis (DTA) results dehydroxylation takes place between $400{ }^{\circ} \mathrm{C}$ and $525^{\circ} \mathrm{C}$. A small amount of water can however persist up to $750{ }^{\circ} \mathrm{C}$ or $800{ }^{\circ} \mathrm{C}$ at which dehydroxylation is complete. Dehydeoxylation of kaolinte was used by Prost $e t \mathrm{al}^{2}$ also using infrared spectroscopy. They observed that among the hydroxyl bands in the $3700-3600 \mathrm{~cm}^{-1}$ region the bands at 3675,3650 and $3630 \mathrm{~cm}^{-1}$ persist after firing to a temperature of $327{ }^{\circ} \mathrm{C}(600 \mathrm{~K})$. According to Elass and oliver ${ }^{3}$, on heating kaolinte the intensity of bands $3700-3600 \mathrm{~cm}^{-1}$ region decreases and at $500{ }^{\circ} \mathrm{C}$ only a weak broad band remains in the $3600 \mathrm{~cm}^{-1}$ region. The thermal behavior of the bands due to hydroxyl groups in clay artifacts were studied by Maniatis $e t a l^{4}$ also. They observed that clay minerals begin to lose their crystalline hydroxyl groups and start disorganizing at temperatures in the range $400-600{ }^{\circ} \mathrm{C}$ and for some minerals it can continue up to $800{ }^{\circ} \mathrm{C}$. According to them the persistence of a weak band around $3600 \mathrm{~cm}^{-1}$ indicates the presence of the iron hydroxyl still in the clay body and points to incomplete dehydroxylation.

The transformation of the clay minerals during heating is reflected in the $1100-1000 \mathrm{~cm}^{-1}$ region also. As the temperature is increased there is gradual destruction of the layer structures of the mineral. The bands at $1105 \mathrm{~cm}^{-1}$ and $915 \mathrm{~cm}^{-1}$ due to $\mathrm{Al}(\mathrm{OH})$ vibrations ${ }^{2,3,5}$ in the octahedral sheet structure begin to disappear with increasing temperatures and at $500{ }^{\circ} \mathrm{C}$ the band at $925{ }^{\circ} \mathrm{C}$ disappears completely ${ }^{3}$. This dehydroxylation is followed by crystal frame work collapse and the tetrahedral sheet disorder can be seen from the broadening of the Si-O stretching bands in this $1100-100 \mathrm{~cm}^{-1}$ region.

The weak shoulder band observed at $875 \mathrm{~cm}^{-1}$ in the spectra of iron rich clay mineral has been attributed to $\mathrm{Fe}(\mathrm{AlOH})$ group present in the clay mineral ${ }^{6}$. The presence of this group indicates the persistence of the octahedral sheet structure in the clay mineral, indicating incomplete dehydroxylation and thus firing temperatures below $800{ }^{\circ} \mathrm{C}$ as at $800{ }^{\circ} \mathrm{C}$ the dehydroxylation of kaolinte minerals are completed ${ }^{1,4}$. However this band is observed only in the iron rich clay minerals ${ }^{6}$.

With these observations regarding the thermal behavior of absorption bands at round $3600 \mathrm{~cm}^{-1}$ region and at $915 \mathrm{~cm}^{-1}$, an attempt is made to establish the firing temperature of the archeological potteries in the present study by FT-IR spectroscopic technique.

Infrared spectroscopy of organic substances has been studied extensively, but its application to the study of inorganic materials, particularly of minerals, is relatively less attempted. Infrared spectra act as "finger print" technique and yield information about the atomic groupings present in the sample. Infrared spectroscopy, which acts as a research tool in mineralogy, is most powerful if used in conjunction with x-ray diffraction and other 
techniques. Using the infrared spectra, unique information about the group of minerals in which the specimen belongs, the degree of crystalline and non-crystalline impurities and reactions of minerals with chemicals in their environment can also inferred.

\section{Experimental}

The samples were collected from two sites Nilgiri and Perumpor of Tamilnadu, India are named as PN \& PP for identification. The samples were taken at depth from soil surface to about $6 \mathrm{~m}$. After removal of surface layers, the pottery shards were grounded into fine powder using agate mortar. They were sieved using a $90 \mu \mathrm{m}$ mesh. The major and minor minerals are qualitatively determined by FT-IR technique. The Perkins Elmer -1600 series available in Indira Gandhi Centre for Atomic Research (IGCAR), Kalpakkam, Tamilnadu is made use of in the present work for recording IR spectra of the samples at room temperature. The $\mathrm{KBr}$ pellet technique (1:20) pellets were followed for the mineral analysis. For each samples five to six pellet specimens were prepared and the spectra were taken in the mid region of 4000-400 $\mathrm{cm}^{-1}$.

\section{Results and Discussion}

The ancient potteries of FT-IR spectra show in Figure 1. The absorption frequencies of the peaks in the spectra of each sample in wave number unit $\left(\mathrm{cm}^{-1}\right)$ are reported in Table 1.

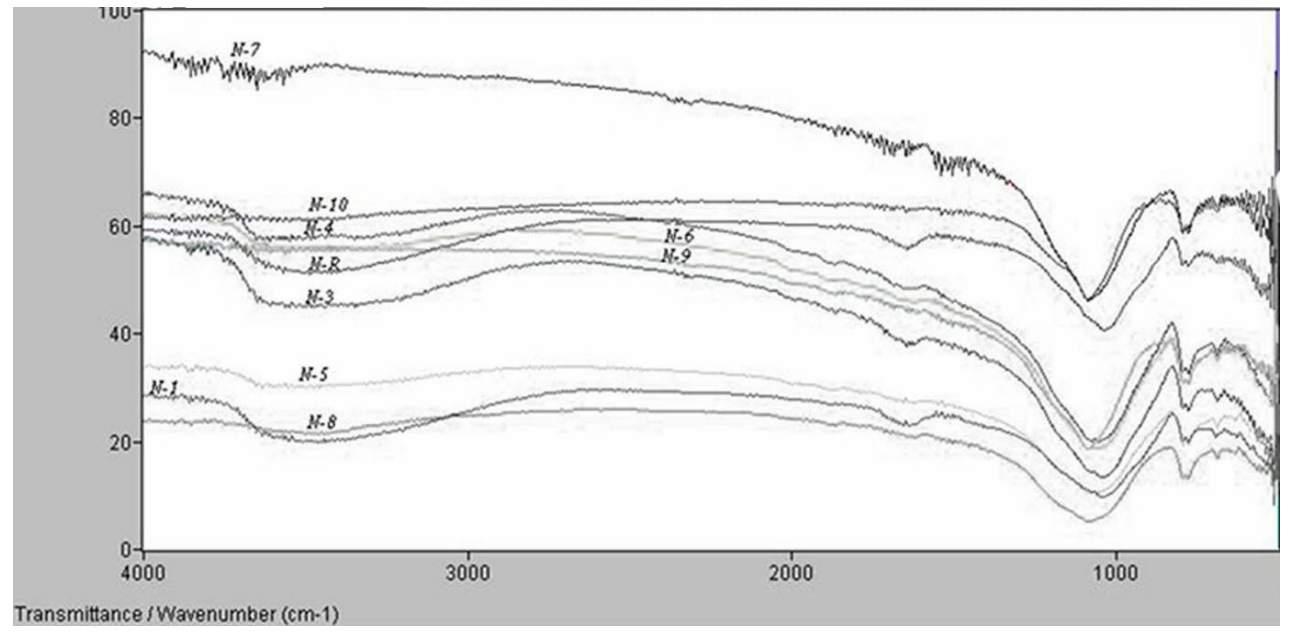

Figure 1. Typical FT-IR spectra of ancient potteries

Table 1. Observed absorption frequency in the region of $400-4000 \mathrm{~cm}^{-1}$

\begin{tabular}{cl}
\hline S. No & \multicolumn{1}{c}{ Observed IR absorption bands $\left(\mathrm{cm}^{-1}\right)$} \\
\hline PN & $405,415,435,445,475,490,535,545,580,605,635,645,675,695$, \\
& $715,775,795,875,1030,1080,3420,36203660,3690$ \\
PP & $405,415,435,445,475,490,545,580,635,605,645,675,715,775$, \\
& $795,875,1030,1030,1080,1425,3420,3620,3690$ \\
\hline
\end{tabular}

The assignment has been made on the basis of characteristics IR wave numbers in minerals. By comparing the observed frequencies with the available literature, the different types of inclusions were identified in the pottery samples such as quartz, orthoclase, albite, hematite, magnetite, kaolinite, calcite, gypsum, montmorillonite and illite ${ }^{7-9}$. The mineral wise discussion is as follows. 


\section{Quartz}

Quartz is a silicate mineral. It could be observed from the Table 1. The IR absorption peaks of quartz are at $445,695,775 \& 795 \mathrm{~cm}^{-1}$ may be due to the presence of quartz in the samples ${ }^{10-13}$. Out of the four peaks observed for quartz, the bands at 795-800 $\mathrm{cm}^{-1}$ and 775-780 $\mathrm{cm}^{-1}$ may be assigned symmetrical stretching modes and those at $695-700 \mathrm{~cm}^{-1}$ and at $445-450 \mathrm{~cm}^{-1}$ may be due to symmetrical bending mode and asymmetrical bending respectively. Out of these two stretching modes and two bending modes $795-800 \mathrm{~cm}^{-1}$ and $695-700 \mathrm{~cm}^{-1}$ are widely used as the diagnostic peaks for quartz.

The presence of quartz gives information about the origin of the potteries; quartz was used in piedmont for covering of engobed pottery, while kaolin was used elsewhere for the same purpose. The presence of quartz may gives information about the samples comes from piedmont or not. It is not possible to state that findings showing quartz inclusions do not being piedmont area. But in the present study the largest parts quartz from the I.R studies may indicates that these samples are common origin.

\section{Feldspar}

From the spectra of the samples in this investigation, the absorption frequencies of the peaks of feldspar were measured together with the literature values. The IR absorption frequency of the bands at $405,435,535$ and $635 \mathrm{~cm}^{-1}$ may suggest the presence of feldspar ${ }^{14,15}$. The peaks at $435 \& 635 \mathrm{~cm}^{-1}$ and $405 \& 535 \mathrm{~cm}^{-1}$ are indicating the presence of orthoclase and albite. Feldspar is a common component of clay minerals. The presence of feldspar, as a common component of potteries, does not give relevant information about the techniques used for their production.

\section{Magnetite and hematite}

Magnetite $\left(\mathrm{Fe}_{3} \mathrm{O}_{4}\right)$ can be identified by band around 670 and $580 \mathrm{~cm}^{-1}$ which is typical spined structures. Hematite $\left(\mathrm{Fe}_{2} \mathrm{O}_{3}\right)$ is observed ${ }^{16}$ by the presence of peaks at 540 and $475 \mathrm{~cm}^{-1}$. The presence of magnetite and hematite provides interesting information about the firing atmosphere. Iron oxides are very influenced by the firing atmosphere; in fact they differ in colour according to firing conditions. When oxygen is almost absent in the kiln i.e. under reducing conditions, reduced compounds as magnetite (black colored) form, on the contrary, under the influence oxidizing conditions, the oxidized form as hematite (reddish) prevail. The presence of hematite in some findings could give further information about the provenance of the clay used for the mixture.

\section{Calcite}

This mineral is characterized ${ }^{17-19}$ by the presence of the peaks at $715,875,1085 \& 1425 \mathrm{~cm}^{-1}$ (Table 1). The presence of calcite $\left(\mathrm{CaCo}_{3}\right)$ in the findings may occur essentially for two reasons; a low firing temperature or a post burial deposition processes. Calcite exits up to $800{ }^{\circ} \mathrm{C}$, when the $\mathrm{CaO}$ formation is promoted, followed by the formation of the so-called "high-temperature crystalline phase" made of Ca-silicates or $\mathrm{Ca}$-Al-silicates such as

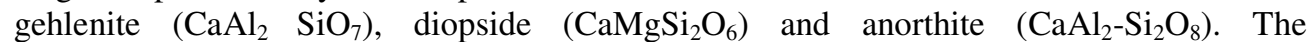
simultaneous presence of calcareous clays of calcite and high temperature minerals clearly rules out any hypothesis of primary calcite, strengthening the assumption of a secondary origin due to deposition induced by water of the burial soil. Clearly in non-calcareous clays calcite is not expected. 


\section{Clay minerals}

The presence of kaolinte, montmorillonite and illte minerals in the samples are from a group of clays. The absorption peaks appearing at 3690, 3660, 3620 and $1030 \mathrm{~cm}^{-1}$ in the samples were attributed to kaolinte ${ }^{16}$. The characteristics feature of kaolinte is the $\mathrm{O}-\mathrm{H}$ stretching band at about 3690 and $3620 \mathrm{~cm}^{-1}$ which can be diagnostic distinguishing kaolinte from other clay minerals. The peak appearing at $3690 \mathrm{~cm}^{-1}$ is the most suitable for both qualitative and quantitative investigation. The absorption band at 3690 and $3620 \mathrm{~cm}^{-1}$ is attributed to the stretching vibrations of inner surface OHs and inner $\mathrm{OH}$ respectively.

The most distinguishing feature of the montmorillonite is the broad absorption bands at the ranges from 3300 to $3500 \mathrm{~cm}^{-1}$. This band typically centered around $3400 \mathrm{~cm}^{-1}$ may be due to $\mathrm{H}-\mathrm{O}-\mathrm{H}$ stretching of water molecules present in the interlayer region of montmorillonite. From the Table 1 , the presence of montmorillonite is shown ${ }^{20}$ by the absorption bands at $3420 \mathrm{~cm}^{-1}$ and $470 \mathrm{~cm}^{-1}$. The IR absorption bands for illite are rarely diagnostic because they are variable in chemical composition. The presence of peak at 490 and $415 \mathrm{~cm}^{-1}$ is attributed to illite ${ }^{20}$.

The gypsum and $\mathrm{MnO}_{2}$ is identified by the absorption peaks (Table 1) at $605 \mathrm{~cm}^{-1}$ and $645 \mathrm{~cm}^{-1}$ respectively ${ }^{21}$. Recently De Benedetto et al. reported the mineralogical compositions of ancient potteries depending upon the IR spectroscopic results. Our results are agreement with those of De Benedetto et $a l^{8}$.

The IR spectra indicates that all the samples contain calcite in different amounts. Calcite is present as impurity of local clays. Observation of calcite $\left(\mathrm{CaCo}_{3}\right)$ bands allows us to draw conclusion on firing temperature. The processing temperature should be below ${ }^{22}$ the decomposition temperature of calcite that is about $700^{\circ}-900{ }^{\circ} \mathrm{C}$. According to mendelovici et al. ${ }^{6}$, the infrared absorption band around $3600 \mathrm{~cm}^{-1}$ is due to hydroxyl groups, which persist up to $800{ }^{\circ} \mathrm{C}$. In the received state PP shows absorption band at $3621 \mathrm{~cm}^{-1}$ which indicates that samples might have been fired below $800{ }^{\circ} \mathrm{C}$ when other sample PN did not show an absorption band at $3621 \mathrm{~cm}^{-1}$ indicating that they would have been fired to temperature $800{ }^{\circ} \mathrm{C}$ or above.

The above results can also be confirmed with the bands at $915 \mathrm{~cm}^{-1}$ and $875 \mathrm{~cm}^{-1}$. The band at $915 \mathrm{~cm}^{-1}$ is due to $\mathrm{Al}(\mathrm{OH})$ vibrations in octahedral sheet structure, which begins to disappear with increasing temperature and at $500{ }^{\circ} \mathrm{C}$ the band disappears completely. None of the samples taken for the present study showed the band at $915 \mathrm{~cm}^{-1}$. This implies that all the samples were fired to the temperature above $500{ }^{\circ} \mathrm{C}$. The broad absorption bands at 580 and $540 \mathrm{~cm}^{-1}$ have been attributed to magnetite and hematite ${ }^{16}$. The amount of magnetite and hematite indicates atmospheric condition of firing ${ }^{23}$. The FT-IR spectra of PP and PN showed the absorption of hematite indicating that these samples were fired in the open air or perfectly oxidizing atmosphere at the time of manufacture.

\section{Conclusion}

Application of IR spectroscopy to ancient pottery shows great potential for understanding technological conditions implemented for production of potteries and found to give useful information about composition of potteries. Quartz, kaolinte and calcite were detected in all the samples. Spectroscopic results indicated that the potteries were fired to a temperature less than $800^{\circ} \mathrm{c}$ in oxidizing atmosphere. 


\section{References}

1. Ross C S and Kerr P F, The kaolin Minerals, U.S. Geol.Survey Profess. Paper. 1931, 165E, 151.

2. Prost R, Dameme A, Huard E, Driard J and Leydecker J P, Clays and Clay Minearls, 1989, 37, 464.

3. Elsass F and Oliver D, Clay Minerals, 1978, 13(3), 299-308.

4. Maniatis J, Katsanos A A and Caskey M E, Archaeometry, 1982, 24, 191.

5. Miller J G, J Phys Chem., 1961, 68, 800.

6. Mendelovici E and Yariv S and Villailba R, Clay Minerals, 1979, 14, 323.

7. Ravisankar R, Rajalakshmi A and Manikandan E, Acta Ciencia Indica, 2006, XXXIIP(3), 341-346.

8. De Benedetto G E, Fabbri B, Gualtieri S, Sabbatini L and Zambonin P G, J Cult Heritage, 2002, 3, 177.

9. Ravisankar R, EARFAM. 2009, 19, 272-276.

10. Hajjaji M, Kacim S, Alami A, El Bouadili A and El-Mountassir M, Appl Clay Sci., 2001, 20, 1-12.

11. Nikolai V Bodoev, Guet J M, Gruber R, Dolgopolov N I, Wishelm J C and Bazarova O, Fuel, 1996, 75(7), 839-842.

12. Boruah R K, Neog A K, Borah P C and Baruah G D, Indian J Eng Mater Sci., 1999, 6, 338-342.

13. Neog A K, Boruah R K, Sahu O P, Borah P C, Ahmed W and Boruah G D, Asian Chem Letts., 1999, 3, 172-175.

14. Fieldes M, Furkert R J and Wells N, New Zealand J Sci., 1972, 15, 615-627.

15. Robert A, Shepherd, Walter S, Kiefert and Graham W R M, Fuel, 1986, 65, 1261.

16. Russell J D, Infrared methods, A Hand Book of Determinative Methods in Clay Mineralogy, (Ed., Wilson, M J,) Blackie \& Son Ltd., 1987.

17. Bottcher M E, Gehlken P L and Steele D F, Solid State Ionics, 1997, 101, 1379-1385.

18. Lopez M C B, Martinez-Alono and Tascon J M D, Appl Spectroscopy, 2000, 54, 1712.

19. SenthilKumar P, Parthasarathy G, Sharma D S, Srinivasan R and Krishnamurthy P, $J$ Geol Soc India, 2001, 58, 15-20.

20. Summer M E, Hand Book of Soil Science, University of Georgia, Boca Raton Hondor Press, New York, 1995.

21. Ghosh S N, J Mater Sci., 1978, 13, 1877.

22. Han R, Shimamotto T, Hirose T, Ree J H and Ando J, Science, 2007, 316, 678.

23. Akyuz S, Akyuz T, Basaran S, Bolcal C and Gillee A, J Molecular Strucuture. 2007, 834, 150-153. 


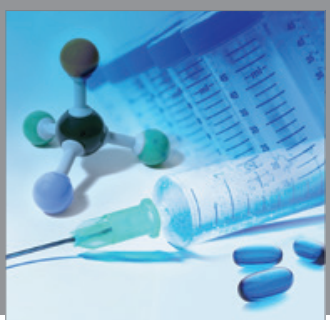

International Journal of

Medicinal Chemistry

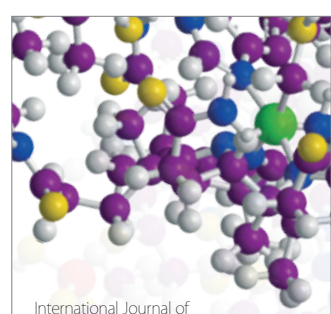

Carbohydrate Chemistry

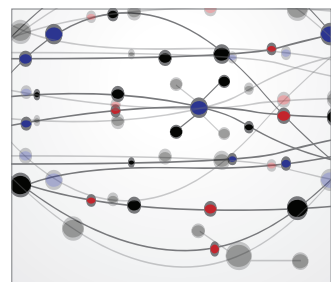

The Scientific World Journal
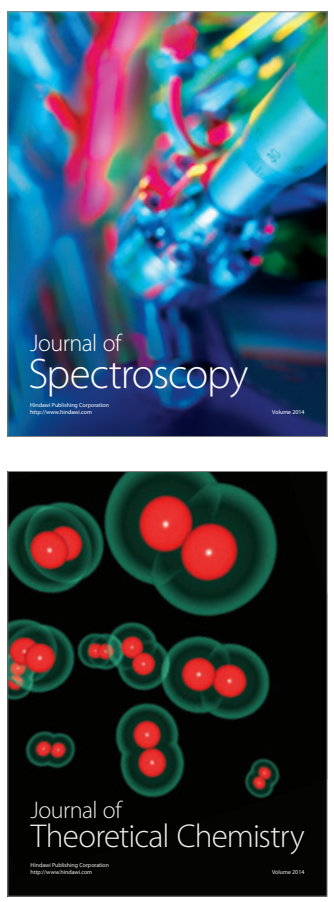
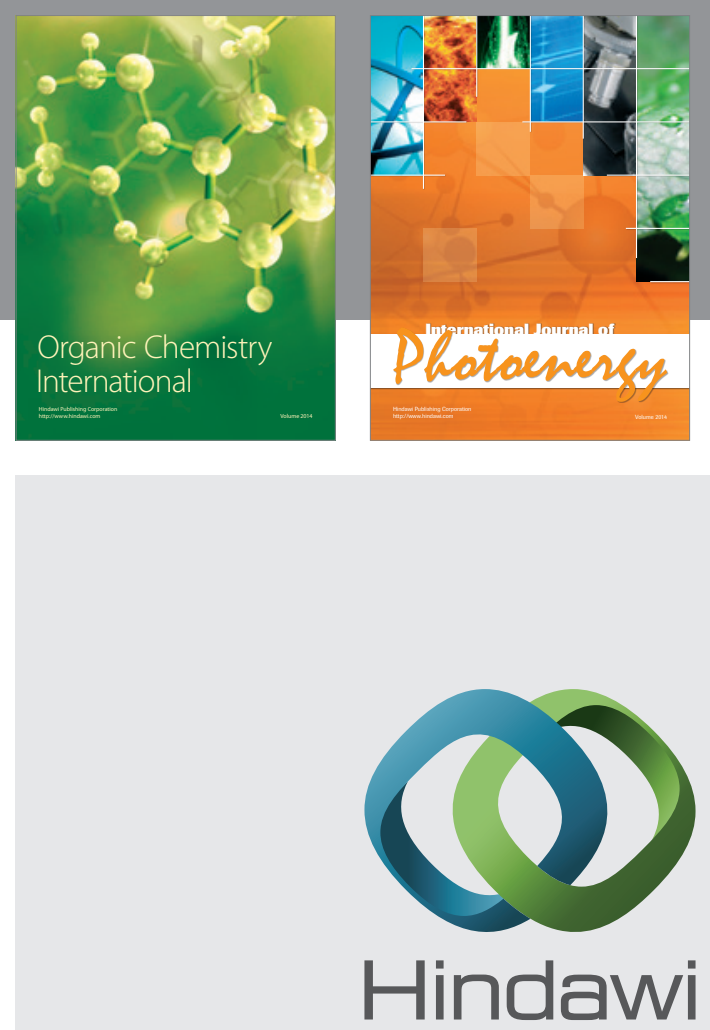

Submit your manuscripts at

http://www.hindawi.com
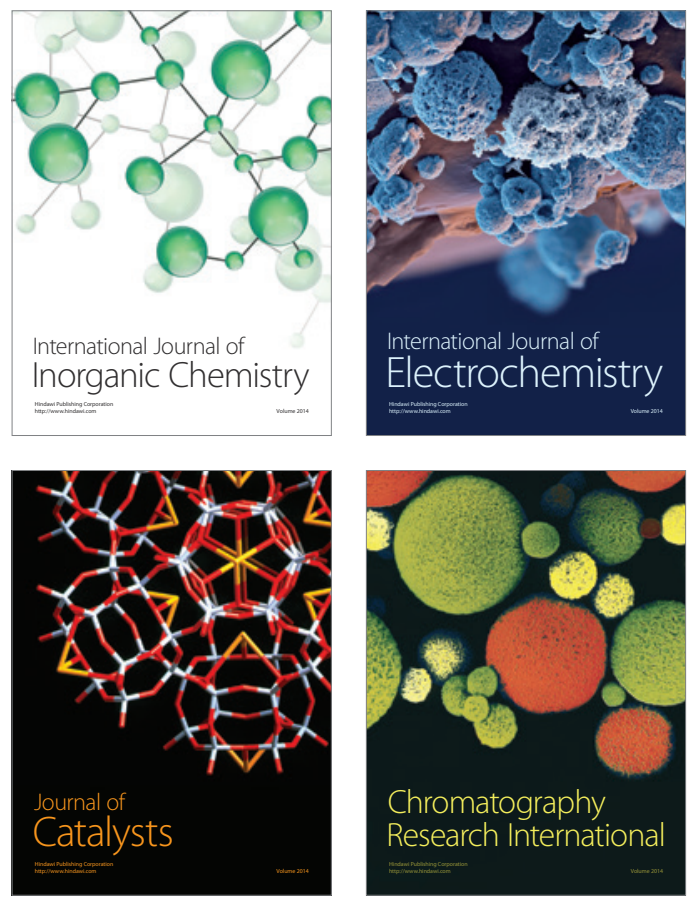
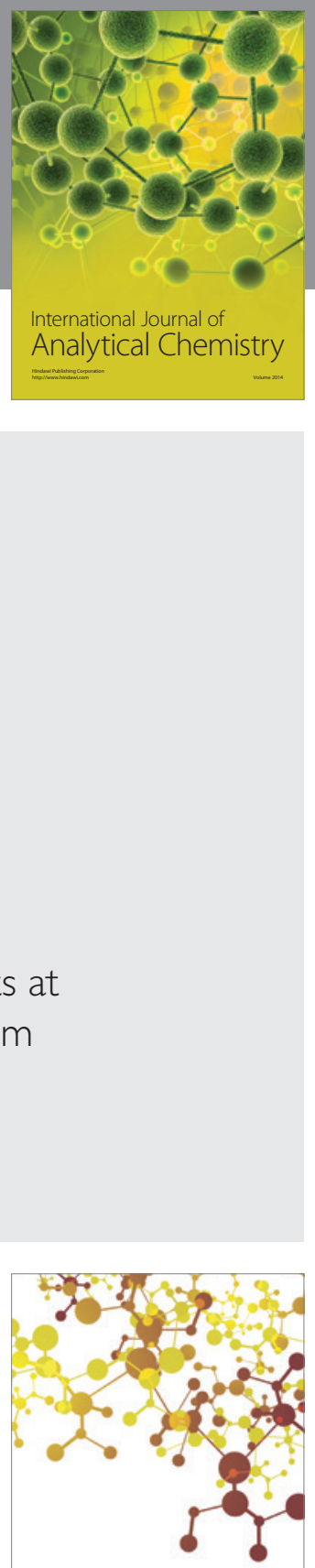

Journal of

Applied Chemistry
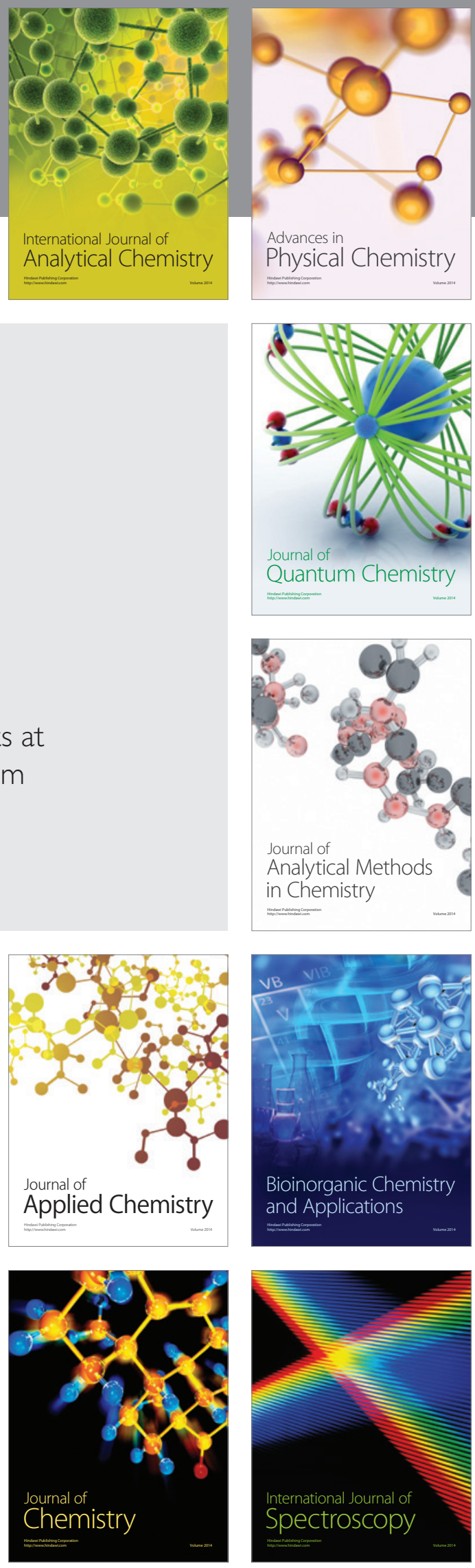